Commonwealth, and afterwards served as physician of the fleet that captured Jamaica. Gideon de Laune died a wealthy and influential citizen.

The ordinance of the Commons, Ist July, I643, guaranteed to the medical men of the army "the same allowances as others formerly had." These were, according to an ordinance dated 23rd March, 1642, "For the Scott's Army, 2 Physicians at 5s., 2 Surgeons at 4s., 4 Mates at 2S., and 2 Apothecaries at 2s. 6d. a-day ;" and I have not learned of any augmentation of this under the Commonwealth.

The same journals show that on each occasion of voting the navy estimates, which was done twice annually, for the summer fleet and for the winter fleet, moneys were granted to defray the cost of "Physicall Drugs and Medicaments for Surgeons' Chests ;" and that on March 24 th, 1648 , when a great part of the fleet had revolted and joined Prince Rupert, an addition was made to the pay of the navy, omitting surgeons; but when a further increase was voted 21 st December, 1652, the pay of surgeons was advanced to $£ 2$ IOs., and that of their mates to $£ \mathrm{I}$ IOs. a month. This augmentation was given to the navy under the pressure of our first naval war with Holland, when the two republics contended for mastery of the narrow seas, when Van Tromp and De Ruyter were the opponents of Blake and Ayscough, in undecided battles, until the 29 th November, when Blake was beaten.

The Parliament took vigorous measures to repair that disaster, and in February, 1653, a succession of defeats of the Dutch induced peace. The war, being entirely a naval one concerning the foreign commerce of the two countries, effected great benefits to seamen. Ships were first rated and ranked; seamen were first classified as able seamen (fit for the helm and lead), and paid at the rate of $24 \mathrm{~s}$. a month net; ordinary seamen receiving I9s. as before; groomets (landsmen), I4s. 3d.; and boys 9s. 6d., after the deductions for Chatham chest, the chaplain, and surgeon. A regulation was made for the supply of medical comforts, at the State's expense, to sick and wounded on board ship, to the extent of ¿5 per 100 men, every six months.

The Protectorate affords our medical naval history no new data, as Cromwell soon exacted humiliating terms of peace immediately on his assumption of supreme authority: the naval power of Spain was speedily subdued by Blake, who died of scurvy on his return to England in 1657 , and Dunkirk was taken from them in 1658 . To the medical affairs subsequent to this, allusion has been already made as a sequel to the resolutions of Parliament in 1652 .

Probably at no period of naval history has the service been more popular than it was towards the end of the Commonwealth and during the Protectorate, when our successes over the Dutch and Spaniards were obtained as the primary and immediate result of the liberal votes and resolutions of the Parliament in 1652 , after the defeat of the great Admiral Blake, who then led our fleets to certain victory, the con. sequence of which cheered the hearts of sailors in a speedy distribution of enormous sums of prize-money, obtained by the capture of richly laden Dutch convoys from the East Indies, and of Spanish galleons laden with the treasures of Mexico and Peru.

Surgeons were not then impressed for the naval service; and, in attaining to that desirable end, we recognise, step by step, the pit out of which the surgical branch of the profession was dug by monarchs and statesmen, whose primary object was to supply fleets and armies with those who would attend to the wants of men wounded in the wars.

At the Restoration, A.D. I660, the entire administration of naval affairs had reached a fresh standpoint, and in no particular more remarkably than in those which appertained to the care of the sick and wounded, many ancient practices being laid aside, many reforms having been established, and new principles asserted and recognised, which it took another century to carry out in their fulness.

I shall pause here, hoping to return to the subject at an early date, and fearing that I may have trespassed on the forbearance of a patient audience.

\section{THE TREATMENT OF SYPHILIS.}

BY JONATHAN HUTCHINSON, F.R.C.S.,

Senior Surgeon to the London Hospital, and to the Hospital for Skin-Diseases.

I II.AVE much pleasure in making such reply as I can to the questions put by "A Liverpool Associate".

In the first place, I would state that the object of my recent paper was rather to attract attention to the evidence in favour of the permanent efficacy of the mercurial treatment of syphilis in its early stages, than to advocate any special mode of its use. I was, however, led almost necessarily, in order to sustain my argument, to insist on the necessity for a long course, and, as a means in order to the practicability of long administration, on the avoidance of doses likely to cause salivation. I had to contend also that the antidotal power of the drug is in no degree of relationship to its full physiological influence; and that the best cures are often those made most quietly. Now, these principles being kept in view, I do not know that there is much to be added as to detail. Begin early; continue long; do not salivate-such would be my rules. I have no strong preference for one kind of mercurial preparation over another; but, as it is convenient to become familiar with one, I have in my own practice of late years almost restricted myself to grey powder. I prescribe it usually in pill, in doses of from one to three grains three times a day, and often in combination with Dover's powder. It is only seldom that an unlooked-for salivation occurs, and it is equally rare to have any trouble with the bowels. Most of my patients continue throughout at their ordinary occupations. A strong reason for preferring to give pills, instead of using inunction or the bath, is, that it is often essential to avoid confinement to the house, and also to run no risk of attracting the attention of the family. Inunction, which is still in general use over the continent, and is without rival at Aix-laChapelle, is a more or less dirty method; can scarcely be concealed from servants; and further, with our English ointment, is very prone to irritate the skin and bring out eczema. As I do not believe that it has any real advantages to compensate for these drawbacks, I never resort to it. The vapour-bath, as proposed by Langston Parker and modified by Mr. Lee, I have the fullest faith in, and have seen excellent results from it in certain intractable cases. It is, however, troublesome, more or less expensive, cannot well be used secretly, and, for all ordinary purposes, it is not in the least necessary. The grey powder does all that could possibly be wished. I must add to this, that I am always particular to use mercury sedulously to the local manifestations of the disease. The chancre is to be soaked with black wash; and to the skineruption an ointment of the ammonio-chloride is almost always applied. If the throat become sore, a gargle of black wash or of the bichloride is usually prescribed.

With regard to the dose, it ought to be sufficient to produce decided effect on the disease. If it be given for an indurated chancre, the hardness ought to begin to diminish within a week. The quantity required in order to effect this will be found, as every one knows, to vary very much in different individuals. A few patients will be met with who appear to resist mercury in a most extraordinary manner, in whom it neither destroys the syphilis nor affects the constitution. As a rough rule, I always expect to have to give more mercury to dark complexioned patients than to others.

The correspondent asks " if some preparations are more adapted to certain stages of the disease-say primary or secondary." In reply, I do not know of any special adaptation of this kind, but find the one I have mentioned the most convenient in all. The bichloride, which at one time I used to give largely in the later forms of secondary disease, $\mathbf{I}$ now rarely prescribe, having become more and more convinced that it is the mercury which is wanted, and not any special preparation of it; and that what is to be aimed at is mainly to choose that form least likely to irritate.

We now come to that part of the letter which concerns the difficult question as to the precise position of the iodide of potassium. Whether this salt is antidotal or not, it is very difficult to say; but $I$ think we may take it as proved, that it is at best very feeble as an antagonist against the early stages of syphilis. It cannot make the indurateck chancre disappear; and I think it does not usually shorten the duration of the secondary rash. A main object of my paper was to protest against its delusive employment in these stages, and to urge that it is false to our patients' interest to permit it to stand in competition with mercury, so far as they are concerned. Even in the case of the most feeble and cachectic patients, it is, I think, a mistake to resort to it, to the exclusion of mercury. But there is much respecting its powers which is yet to be made out. The rapidity and certainty with which it will cure some forms of tertiary disease are very wonderful; and from the inveteracy which these used to assume prior to its introduction, we may, I think, safely infer that the mercurial methods then in vogue were not successful. Of late years, mercury has been but very rarely tried for tertiary disease; and I for one may freely confess that I am not in possession of any large number of facts respecting it. Whether or not it might in certain cases cure more permanently than the iodide, I have no means of knowing; whilst that it would prove prejudicial in many, is, I think, highly probable. Now, if the theory which I have advanced as regards the distinction between the secondary and tertiary maladies be true-that the former are due to blood-changes, and the latter to those of tissue-it possibly follows that we ought not to expect anything of the nature of prevention from the remedies which we use against the latter. It is enough if they cause the local inflammation to cease, and not possible that they should alter the constitution of the solid tissues, 
built up as they have been years ago from a tainted blood. My impression is, that this conjectural view is supported by clinical experience, and that we do not find any benefit from continuing the iodide after the local cure has been completed. I think this answers the last query put to me; but, if there be any points upon which my explanation may be considered not sufficiently explicit, I will gladly make a further attempt.

\section{CASES WHERE DEATH HAS FOLLOWED THE IN- JECTION OF THE PERCHLORIDE OF IRON INTO THE UTERUS TO ARREST POST $P A R T U M$ HÆMORRHAGE.}

\section{By T. SNOW BECK, M.D.Lond., F.R.S.}

In a review, published in the Edinburgh Medical Review for the present month, of Dr. R. Barnes's work, $A$ Clinical History of the Medical and Surgical Diseases of Women, it is said, "he (Dr. Barnes) has the manner of a schoolmaster towards all those who differ from him. He is always laying down principles and theories ;" and, if I might complete the picture, I would add, " and himself constantly violating the principles he lays down." Dr. Barnes's " clinical experience" is also characterised in the same review as "an example of fireside, not bedside, description," the "fireside descriptions," it may be added, being so frequently inaccurate, that they amount to descriptions the contrary to the facts. Different examples of these "fireside" inaccuracies occur in Dr. Barnes's recent communications; but I will only advert to two of them. I have never said that I " had seen death from septicremia following the injection of the perchloride of iron into the uterus to arrest post partum hæmorrhage," though a case of this affection after injection with the perchloride of iron is reported by P. B. Giles, junior, in the Obstetrical Fournal, No. vii, p. 442. But I have said that the symptoms observed in the fatal cases which have followed the injection of the perchloride of iron to arrest post partum hremorrhage, greatly resemble the symptoms attending puerperal septicæmia, but differ from them in being apparently even more fatal, and, so far as we at present know, in there not being any means by which the fatal termination can be averted.

With reference to the charge of "persistently evading the plain duty incumbent upon us all to set forth the facts from which alone scientific conclusions can be drawn," I would merely state the following facts. In September 1872, I forwarded to the secretary of the Obstetrical Society, Dr. W. S. Playfair, some of the following cases, with a commentary. After a few weeks, I was informed that the president, Dr. Braxton Hicks, considered the paper to be of a "controversial character," and, as the statements contained in it differed from those which Dr. Barnes had previously made on the same subject, the paper could not be allowed to be read. After the experience I had previously had, this announcement did not surprise me; and I decided to print these cases, with others, in a separate form; the papers which have appeared in the Obstetrical fournal being portions taken from the manuscript which I drew up with this intention. However, it was found impossible to exclude the subject altogether from the Society, and the case which occurred in the practice of Dr. Heywood Smith was, after considerable difficulty, admitted and read; but all expression of opinion contrary to the views of Dr. Barnes and Dr. Braxton Hicks was endeavoured to be suppressed by noisy clamour. At this meeting, the uterus and appendages were placed before the Society ; drawings of the appearances they presented were made and shown; Dr. Barnes was present, and might have satisfied himself as to the accuracy of the drawings, and the description of the appearances in the preparation; but he never examined the uterus and appendlages submitted to the Society. This preparation, with others, also remained in my house for months, were seen by some of the Fellows of the Society, and might have been seen by all. Truly, it is said, "there are none so blind as those who won't see."

The following cases were drawn up for publication in the present form. They are given in considerable, perhaps tedious, detail; but, as the facts they demonstrate have been, and probably may continue to be, much disputed, I have thought it better to give them in full.

CASE 1.-A. C., aged 30 years, was admitted into the British Lying-in Hospital, under Dr. Heywood Smith, at 2.30 A.M. on January 26th, 1872, in labour with her fourth child. Her previous history, as far as could be gathered from her friends, was, that she had been twice married; during her first marriage, she had two children, besides two miscarriages, with both of which latter she had severe floodings; during the second marriage, she had also had two miscarriages, with severe loss at each, that with the last being so serious that she was obliged to keep her bed for four months. Her health between the pregnancies was reported to have been pretty good.

January 26th. She was delivered naturally by a pupil midwife, at
4.20 P.M., of a male living child, weighing eight pounds fourteen ounces, after a labour of twelve hours' duration. The placenta came away easily twenty-five minutes after the birth of the child, with not more than the usual loss of blood.

January 28th. She was previously doing well ; the lochia natural, without offensive odour; the milk came yesterday afternoon. About 3 A.M., she awoke with a severe pain at the hypogastrium, and from this time the lochia were rather scanty; the bowels not open.

February $4^{\text {th. }}$. Tenth day. Three days ago, she was moved downstairs in a chair, but had not been out of bed before or since. Yesterday morning, some hæmorrhage occurred, with slight pain, and, this morning, she passed several clots ; nothing had occurred to account for this bleeding; pulse 76 ; tongue clean; the orifice of the uterus patent as far as the inner os, and bleeding. She was ordered thirty grains of ergot of rye every four hours.

February 5th. Eleventh day. The orifice of the uterus was not so patent; it lay high up, and backwards. She had very little pain from taking the ergot of rye. Bleeding continued yesterday till the evening, and commenced again this morning. The uterus was injected with one part of liquor ferri perchloridi, and eight parts of water, with Higginson's syringe, and a long elastic tube was passed into the uterus.

February Ioth. Sixteenth day. The uterus was again injected in the same manner as before, with liquor ferri perchloridi and water. I believe the bleeding had never actually ceased; and, though it was much lessened, still some discharge of blood continued.

February 14th. Twentieth day. Bleeding returned on the night of the $\mathrm{I} I \mathrm{th}$, and the uterus was again injected on the $\mathrm{I}$ th with one part of liquor ferm perchloridi and four parts of water. It was again injected to-day with equal parts of liquor ferri perchloridi and water. No bad symptom had followed any of these injections; no pain ; appetite and spirits good ; she slept well.

February 15th. Twenty-first day. The uterus was again injected at II A.M. with strong liquor ferri perchloridi, using the intrauterine syringe, which holds about half an ounce, but only about two drachms were injected. Very severe and sharp pain at the lower part of the stomach directly followed, and, from this time till the evening, she rolled about in the bed with severe pain. She said she "felt as if something had been torn out of her." Poultices were applied to the hypogastrium, but the pain was not relieved till the evening; she was violently sick; no bleeding occurred after this injection. The colour of the blood was bright red, not dark; latterly, the bleeding ceased after each injection, and recurred again a little before it was repeated ; it was a continuous oozing, but never amounted to a flooding.

February I 7 th. Twenty-third day. Noon.-Pulse 140, full, weak ; tongue dry at sides; she was feeling very weak ; in no pain ; there was a slight coloured discharge; she was ordered cinchona, ammonia, and opium. II P.M.-Pulse I60; temperature 104.3; respiration 32 ; tongue dry in the centre, moist at the sides; abdomen distencled ; she vomited everything; had been delirious this afternoon and evening; no. bleeding per vaoinam, but a brown and offensive discharge. Hydrocyanic acid with carbonate of soda were prescribed for the sickness, also one minim of tincture of aconite every half-hour.

February i8th. Twenty-fourth day. II A.M.-Pulse I48; temperature I04. I ; respiration 24 ; tongue moister; abdomen distended; she was not in so much pain, and had not been sick after the second dose of the hydrocyanic acid mixture. IO P.M. - Pulse I40; temperature IO3; respiration 24; abdomen softer; she had had seven or eight full evacuations from the bowels, passed urine, and slept a little; she had been free from sickness all day, till now.

February Igth. Twenty-fifth day. 3.15 P.M.-Pulse 168 ; temperature 105.4; tongue darkish; she took her food well; the bowels had acted ; motions not relaxed; there was occasionally great dyspnoa ; no pain ; she had cough, and expectorated froth; there was kicking of the bed-clothes. I I P.M. - She was in a cold sweat, sinking.

February 20th. Twenty-sixth day. Io A.M.-Pulse 152 ; temperature I05.I; respiration 52; tongue moister and cleaner; abdomen softer ; no pain ; she slept in the night; had eight ounces of brandy in the night. IO. 15 P.M.-Pulse 160 ; temperature 103 ; respiration 48 ; tongue dry in the middle, and moist at the sides. She fiad ten ounces of brandy, one pint of ale, a little meat and beef-tea.

February 21st. Twenty-seventh day. Pulse I 44 ; temperature 99.4 ; respiration 36 ; tongue moister; she had been verydelirious and violent; dill not sleep. II P.M.-Pulse 140 ; temperature IOI.2; respiration 44 ; tongue moist; she had not been sick since morning; right eyelid swollen; urine bright coloured; diarrhœa since 2.30 P.M.

February 22nd. She died at 8 A.M., the twenty-eighth day after the confinement, and the seventh day after the supervention of the symptoms.

The uterus was large, measuring about five inches long by four inckes 